\title{
JUANA Y LA CIBERNÉTICA (1963)
}

\author{
Elena Aldunate
}

"¿Qué estúpido sería -pensó la mujer- que por una chapa descompuesta me fuera a quedar encerrada!". Dominando la alarma que solapadamente comenzaba a entorpecer sus dedos, hizo un nuevo intento. La llave se quebró. ¡Diablos!..., ahora sí que la situación no tenía remedio. Salvo que alguien se hubiera quedado por ahí. A veces el señor Morales se retrasaba ordenando las tarjetas para el lunes... La esperanza la hizo musitar su nombre. Después, alzar la voz para llamar. ¡Nada! ¡Nadie! No hubo respuesta. El taller era bastante grande, pero no tanto como para que si alguien se encontrara entre las máquinas o en las oficinas, no la oyera. Al escudriñar, vio la sala irremediablemente vacía. Sus oídos captaron el silencio. Mientras forcejeaba con la llave, no se había percatado de él, pero ahora, tras el eco de su grito, la sobrecogía como una mano inesperada.

¿Para qué diablos volvería a buscar el chaleco? La inutilidad de la prenda pesaba sobre sus hombros. ¿Para qué? ¿Para qué?... Nada ganaba con reconvenirse; la cosa estaba hecha. La única puerta de salida era esa en cuya chapa la llave, quebrada, relucía malignamente. Muy altas quedaban las ventanas; la fábrica tenía cuatro pisos. Las paredes eran lisas y la puerta de fierro. Solo las máquinas, grises y complicadas, con la indiferencia de los animales domésticos, contemplaban su pequeño drama.

De pronto, una idea la hizo correr al lavabo. ¡El tragaluz se comunicaba con todos los pisos! A veces había escuchado trozos de conversaciones. No les prestó atención, pero parecía que las personas estaban cerca. Ahora lo recordaba. A lo mejor, alguna de las secretarias se arreglaba todavía.

Sus pasos precipitados resonaron en las baldosas. La fila del lavatorio relumbró en la oscuridad. Urgiendo agilidad, en su miedo, la mujer trepó sobre uno de los lavatorios, y, formando una bocina con ambas manos, gritó... Convertida, toda ella, en un gran oído, esperó. ¡Nada! Silencio. Gritó y volvió a gritar. Los ecos se acallaron.

Entonces la mujer tomó conciencia de su situación, y el comienzo de un sollozo incontrolable la contrajo. Tendría que pasar tres días encerrada ahí. Sola, asustada, hambrienta. Era una suerte, no obstante, que la avaricia del señor Wellmann lo moviese a construir los servicios higiénicos dentro de las grandes salas de máquinas. Su objetivo había sido mantener a las obreras bajo su control; ahora ella lo bendecía. Pero eran tres días: sábado, domingo, lunes..., y en vísperas de Año Nuevo. ¡Era el colmo!

¿Quién le daría de comer a Cascabel? ¿Quién le limpiaría la jaula? A lo mejor, en la cena de tía Lucha, esta le echaría de menos; le extrañaría no verla llegar. Era la única parienta con la cual pasaba la noche abominable, bulliciosa, triste, de Año Nuevo. Pero tía Lucha pensaría que la habían invitado a otro lugar. Nadie más podría extrañar su presencia. Quizá la señora Carmen. Al fin y al cabo esa pensión era su hogar desde hacía nueve años. ¡Su hogar!... ¡Cuánto soñó con tenerlo!... ¡Y qué diferente habría sido su 
hogar de esa pieza pequeña y atiborrada de objetos diversos atesorados tontamente en el transcurso de una vida monótona y descolorida!

Pero de todas sus compañeras de trabajo, venía a sucederle a ella este percance idiota. A ella, a la que vivía sola. A ella, que en sus cuarenta y cuatro años no conociera el amor..., al hombre.

¿Por qué este pensamiento tan íntimo, tan mañosamente oculto, tan fuera de lugar, en estos momentos se le hacía presente de súbito, de golpe?

Sí; era la verdad. Ella, una mujer no demasiado religiosa, sin tantos prejuicios, no $\tan$ fea..., no sabía físicamente lo que era un hombre, cómo era un hombre. Siempre trabajando, siempre viviendo, en calidad de allegada, donde tía Lucha. Pospuesta, mal vestida, al margen de la existencia, de los sinsabores y de las alegrías de los demás. Para colmo, tímida. ¿Por qué pensaba en eso ahora? Tal vez por una vaga sensación de muerte, de término... De pronto, sintió ganas de reír. ¿Qué perdía con estar ahí, encerrada? ¿Alguna cita? Solo había tenido dos citas en su vida. Menos todavía, porque una de estas fue un error. ¿Una broma tal vez? La cara del señor en cuestión se presentaba vivamente en su recuerdo: “Pero, usted no es la señorita Blanca?”. Sí, había sido una humillación, un desencanto. Perdería la cena con tía Lucha. Una cena pobre en una casa pobre y sucia y oscura, llena, en ese, cuando ella vivía allá, de chiquillos gritones, de ropa por lavar. Hoy en día, llena de muchachitas impertinentes y arremilgadas: sus primas. No; nada perdía con no estar en esa comida. Como siempre, por no tener servidumbre, tía Lucha le habría dicho: “¡Ay, Juanita!, usted que tiene tan buena voluntad...". Nada tenía que perder, y a nadie haría falta. En cuanto a Cascabel, ipobre Cascabel!, la señora Carmen lo vería.

Salió de la sala de lavabos. El reloj, adosado al muro, indicaba la 1.30. A través de las altas ventanas, el sol veraniego calentaba el lugar, iluminándolo todo en exceso. Por los rayos que cruzaban la sala, millones y millones de partículas de polvo subían y bajaban silenciosas. ¡El silencio! Eso era lo peor. Si al menos hubiese llevado el tejido, como casi todos los días. Pero no, esa mañana todo le había salido al revés. En el barrio, la electricidad había amanecido cortada, y tuvo que preparar el desayuno, a escape, en el anafe a parafina. Esto le hizo retrasarse en media hora, recibiendo la reprimenda del señor Morales. Tampoco había nada que leer. Nada con lo cual entretenerse. Nada en qué pensar..., tan poco para recordar.

Trata de tranquilizarse. Se pasea entre las máquinas. Intenta familiarizarse con el ambiente. Hace calor. Tiene el maldito chaleco y tiene agua, aire y espacio para caminar. Contra la pared, alineados, los bancos para que las operarias se sienten a merendar en la media hora concedida. Puede tenderse en uno de ellos y dormir. Tal vez el hambre no sea tanta, y nadie vendrá a apurarla. Nadie se preocupará de ella durante dos días y medio, lo que no deja de ser una ventaja. A lo mejor, ¿por qué no?, puede convertirse en alguien célebre y hasta salir en los periódicos. "La mujer que pasó tres días encerrada en una sala de máquinas". Probablemente este suceso insólito hasta puede servirle a la fábrica como propaganda. Podría ocurrírsele al señor Wellmann hasta subirle el sueldo. Con este aumento ¡compraría la máquina de coser!... Esa máquina de coser que ambiciona desde hace tanto tiempo, y que todos los días contempla al pasar ante la vitrina de 
esa tienda. Hasta puede que, gracias a esta tonta aventura, su vida monótona y aburrida tome otros rumbos. A lo mejor, por fin, un Dios, o lo que sea que por allá arriba o aquí abajo se las dé de tal..., se ha acordado de ella.

Su mano, distraída, se apoya en una de las palancas, y sus pasos, movidos por la rutina diaria, la conducen hasta su puesto de trabajo. Hasta "su" maquina. La mira con cariño. Hace dos años que trabaja con ella; la conoce, sabe sus movimientos, sabe de sus engranajes. Esta tarde la siente viva, compadeciéndola. Mueve ahora la palanca. Nada pasa. Entonces recuerda que los conmutadores están situados al fondo de la sala, y que los desconectan todas las tardes. Cruzando con lentitud la sala, llega hasta la gran caja donde las negras manillas relumbran al sol. ¿Cuál será? Con las dos manos baja la primera. Un rumor sordo indica que algún efecto ha logrado. Vuelve a su puesto habitual, ante la máquina. No; no funciona. No es aquella manija. Retorna a la caja de conmutadores: cierra la primera y abre, bajándola, la segunda... En la tercera fila, una máquina comienza su rítmico movimiento. ¡Es la suya, es su máquina! Con alegría infantil, la observa por primera vez con curiosidad. Ya no con esa distraída dedicación que su peligroso oficio requiere: poner y sacar las delgadas planchas de zinc. No, ahora la observa con interés. El ruido sordo, interrumpido rítmicamente por el golpe seco de la perforadora, la va tranquilizando. Imagina sentir voces a su alrededor; voces que la acompañan, como siempre. Sentada ante la máquina, la observa detenidamente. ¡Qué precisa, qué recia, qué perfecta es! Imagina, de pronto, lo que sucedería si metiera una de las manos bajo el tubo redondo y hueco. Su mano quedaría como en esos cuadros modernistas, en que las figuras, perforadas, dejan ver el paisaje. ¿Y si la máquina se negara a hacerle daño, se negara a continuar?... Está imaginando tonterías. Es una máquina y nada más que una máquina. Por hacer algo, saca de debajo de la plataforma una de las planchas de hojalata, y, con movimientos expertos, la introduce en la bandeja móvil. La máquina responde, cogiéndola con sus extraños dedos, y dándola vuelta con rapidez precisa, asesta sobre ella tres certeros golpes... abriendo tres agujeros redondos, del porte de un puño. Luego, el trozo cortado se deposita en la cinta transportadora, la que, por estar detenida, produce un ruido seco. El trabajo de la mujer es monótono y no demanda imaginación. Rapidez, control de los movimientos, y un sí es no es de atención. Pero, para un ser con fantasía como la suya, ofrece libertad para soñar, para vivir tantas historias que jamás sucederán. Quizás hace dos años, cuando su cuñada le ofreció el puesto en la fábrica, lo aceptó por eso. Pero nunca imaginó una aventura como la que está viviendo...

¿Tendrán ojos las máquinas? ¿Tendrán boca? ¿Se asemejarán en algo a la imagen de su creador, el hombre? El hombre, Dios y Señor de la Creación. Recordó conversaciones entre sus compañeras, páginas leídas en diarios o revistas: "Un día las máquinas se rebelarán contra sus amos. No necesitarán de ellos y tendrán iniciativas". Por otra parte: "El aumento de las máquinas, mil veces más rápidas, precisas y seguras que la mano o el ojo humano, produce la desocupación obrera. Los robots...".

Inquieta, mira en su derredor y baja la palanca. El silencio, acompañado por el monótono zumbido de los conmutadores, se hace presente. De la calle suben presencias humanas. No es una calle muy concurrida, las casas quedan aisladas. En los días festivos 
el barrio se sume en la quietud. Pone una banca sobre la otra y trata de alcanzar la ventana. No; decididamente la ayuda no vendrá por ahí. Vuelve a colocar las bancas donde estaban. ¿Para qué apresurarse? Sentada, con la espalda apoyada en el muro y estiradas las piernas, saca mentalmente cuenta de las horas que tiene por delante. ¡Permanecerá encerrada sesenta horas! Fue una lástima no haber traído el tejido. La ociosidad la irrita. Podría haber adelantado en el trabajo; pero nada puede hacer sola, porque las planchas de zinc son acondicionadas y perforadas en un trabajo en cadena con el de otras operarias.

Ya son las tres de la tarde. ¡Qué lentas pasan las horas! Tiene hambre. El desayuno, tomado a la carrea, fue escaso: té puro. Lleva ocho horas sin comer, y tendrá que soportar mucho más. Adentro le duele algo, su boca está seca.

Piensa, divertida, que usando la imaginación puede tomar un almuerzo líquido: agua. Va a los lavatorios y enjuaga dos vasos plásticos, los llena de agua y va con ellos a sentarse afuera. Lentamente va apurando el insípido y transparente líquido... Primero es un plato de consomé, luego, huevos con jamón; por último, un postre de frutas, y todo esto, acompañado por un gran vaso de leche.

Pasan las horas, y todo comienza de nuevo: la soledad, el aburrimiento, el pasearse, el discurrir y el hambre. Y viene el sueño. Hace una especie de nido con toallas de papel, huaipe y dos bancas. Por suerte, tiene en su cartera el frasco con pastillas tranquilizantes que le recomendaron esa vez. Toma tres. Quiere dormir, y que el tiempo pase...

Son las once cuando despierta entumecida y acalambrada. ¡Qué cansancio, qué hambre! Comenzará el día como siempre, con una taza de leche caliente, unas tostadas y la ducha. Por fin tendrá tiempo para darse un baño largo y perezoso con el que ha soñado tantas veces. En la sala de baño se lava los dientes y bebe un vaso de agua. Siempre su bolso está bien provisto, lleva de todo, hasta jabón: no le agrada el olor a desinfectante que dan esas pastillas que hay en la fábrica. Con lentitud se desnuda, y, al ordenar su ropa, se demora mucho, mucho, pero... no lo suficiente. Al pasar ante los grandes espejos, se contempla. Nunca lo hace desnuda. El espejo le muestra a una mujer delgada, un tanto angulosa, blanca, demasiado blanca; la cintura algo gruesa. A los veinte años debió tener un cuerpo bastante hermoso. Ya nadie lo sabrá. Levantando los brazos, como lo viera hacer en más de un filme francés, se recoge los cortos cabellos en la nuca y una adormecida coquetería la envuelve. Con absurdos contoneos se introduce en una de las casetas y abre la llave del agua caliente. Espera unos instantes, y el vapor, al salir, le indica que las calderas aún no se han enfriado. Luego, el agua tibia corre acariciante por su piel, por su rostro, por su cabello, por sus manos, por sus hombros huérfanos de dedos masculinos, por sus pequeños pechos aún duros, por sus puntudas caderas yermas, por sus piernas cansadas y sus pies demasiado anchos. Los ojos cerrados, la boca abierta bajo el chorro, Juana sueña... Después, se enjabona minuciosamente. Demora mucho, mucho, hasta que la piel se arruga e irrita. Con la cabeza blanca de espuma, sale para mirarse otra vez en los espejos. Ante estos, se inventa disparatados peinados. Luego, sonámbula, se pasea desnuda y empapada por la sala. ¡Qué maravillosa sensación! 
El sol en su piel húmeda, en sus caderas ruborizadas. El aire entre sus pechos y sus piernas. Libre, impúdica, sola. ¿Y si alguien entrara? Pepe, el nochero, tal vez hará su ronda. Pero no; algo se ha rumoreado, entre las empleadas, que al viejo Pepe lo echaron por no aceptar el quedarse la noche de Año Nuevo. ¡Pobre hombre! Ella le encuentra razón: cuántos años al servicio del señor Wellmann, y no pueden concederle una gracia para la noche de Año Nuevo... De pronto siente que la están mirando; que muchos pares de ojos la observan. Con nerviosos grititos, corre a esconderse en la ducha, la cual, contra su costumbre de ahorro, ha dejado abierta, y se enjuaga. Más tranquila, vuelve a la sala para secarse al sol. No podría mojar las toallas de papel, que son su cama y abrigo. En el centro de la sala, se tiende de espaldas sobre una de las bancas. Son las dos y hace calor. Siente pena, angustia, desazón, hambre. Pero se arregla los cabellos y se viste. Todo eso, ¿para qué?, ¿para quién? Qué tremendo es el tener tiempo; tiempo para pensar lo que ha hecho de su vida. A pesar de la lentitud que toma en observarlo, de la lentitud con que se incorpora, cruza la sala, se viste y se seca el pelo...; las horas son las mismas, y los minutos corren de cinco en cinco. Recomienza toda la larga espera, hasta que la oscuridad llega. Acomodada en su lecho de papel, cierra los ojos; pero no puede conciliar el sueño. No puede dormir. ¿Por qué tendría que dormir? Esa es una costumbre adquirida: "En la noche se debe dormir". "En la mañana se trabaja, se limpia la casa. Almuerzo a las doce. Hay que tener hambre...". ¿Hambre? Luego se retorna al trabajo y a las seis se va al cine; a las ocho hay que tener una cita o leer un libro, o morirse de pena. No; en los días que le quedan, ella no seguirá esta corriente; ella romperá estas leyes e impondrá las suyas, satisfará sus deseos postergados. Irá al cine. ¿Por qué no?

Los tres conmutadores han sido conectados. Las máquinas de la tercera fila trabajan con su ruido sordo, vibrante. Sentada, con la espalda apoyada en el muro, la vista perdida en la nada, ve cómo el galán, inclinado sobre la heroína, besa sus cabellos perfectamente ordenados y peinados; la respiración de él es anhelante, acelerada, ronca. La de ella, alerta, trémula, entregada...Y las horas pasan. Juana imagina muchas cosas y las sensaciones se suceden. Recuerda escenas vividas y calles y luces y melodías. Voces. La claridad de afuera da a la sala un feérico reflejo. Entre las máquinas, la mujer camina calle arriba y calle abajo. Sus manos sobre los metales en función. Calle arriba, calle abajo. Detenida ante la máquina fija sus ojos en ella y una atracción irresistible la obliga a tocarla más próximamente. Tiene hambre, malestar, mareos, dolor y miedo. La máquina la conforta, es lo único familiar en su abandono. Y comienza el juego: los dedos, bajo el grueso y perforante émbolo. Juana sonríe. A cada movimiento de la máquina, ella es más rápida. Mucho más rápida. Existe la ventaja de que la máquina no aumentará, no puede aumentar, su velocidad; por lo tanto, siempre ella ganará. Siempre sube y baja, a la derecha, a la izquierda, y siempre sus manos pálidas son más rápidas. El calor de la fricción da al acero tibio contacto; la repetición del movimiento, un jadear rítmico. Engranajes aceitados que giran, se encuentran, se separan..., se encuentran, se separan... Voces que parecen surgir de ese silencio, del ruido continuado y dormido, voces que murmuran: "Juana, Juana, Juana...". Las manos embadurnadas de aceite, inclinada sobre la máquina, la mujer sueña: aceite, hambre, sabor, tibio sabor, viscoso... Ya no sabe si es malo, si es repugnante. Tiene hambre. Su lengua lame el espeso líquido que 
envuelve el redondo acero. No es malo: sabe a sangre, a sangre oscura y gruesa, saliva, savia. ¿De qué estará hecho el aceite? ¿Será veneno? Ahí, debajo de sus pies, está el aceitero con el que, a veces, tiene que lubricar los ajustes del eje. Del pequeño tarro deja caer una gota en la palma de su mano. ¡No; no tiene tanta hambre como para eso! ¿Hambre? ¡Ya lo creo que tiene hambre!, un hambre atroz, adormilante, una necesidad ya casi olvidada; un vacío, un permanente dolor. Sin embargo, no piensa ya en comer ni en qué le gustaría comer. No; esa es un hambre prosaica; tiene hambre de vida, de poder, de redención. Sus ojos, que recorren la sala como buscando, dan con los cristales de las grandes ventanas. Sol... ¡No puede ser otra vez de día! ¿Cómo pasó el tiempo? ¿Qué hizo todas esas horas? ¡Ah, sí! Fue al cine y tuvo una cita. Una cita que duró toda la noche y la madrugada también, como la soñara... Tiene hambre. Se levanta y, lamiéndose los dedos, va hasta los lavatorios. El jabón ennegrecido se escurre de sus manos. Lentamente, bebe agua... "café, carne, naranjas". Una y otra vez. No puede más, no puede más. Va a vomitar. Las máquinas siguen, allá afuera, su acompasado ritmo, su latir sordo. Hay que cortar los conmutadores. Pero, ¿para qué? ¿Qué importa si la acompaña tanto el movimiento de las máquinas? "Juana... Juana... Juana...". Nadie la ha llamado jamás con esa suavidad, con esa insistencia. De nuevo ante la máquina, aprisiona entre sus manos pálidas y olorosas la tibieza del émbolo que sube y baja, a la derecha, a la izquierda; preciso, potente, seguro. "Juana... Juana...". Y el juego recomienza. De pronto el chaleco gris que pende de sus hombros es aprisionado en uno de sus movimientos. La máquina se atasca por unos instantes; luego, en la cinta transportadora, hacen su aparición los despojos negros. ¡Qué torpe ha sido! Enojada, Juana baja la palanca y cruza la sala. ¿Cuántas son las máquinas en movimiento? Solo tres. No; ¡hay que hacerlas andar a todas, a todas! Quiere calor, ruido, mucho ruido, mucha vida. Como posesa, corre entre ellas, bajando palancas, apretando botones, abriendo válvulas..., todas las máquinas están a su disposición y bajo su dominio. El suelo trepida, es insoportable el calor, la sala entera rechina, jadea, se lamenta, ríe, murmura. Así se puede dormir, ¿verdad? ¿Quién dijo que el silencio era precursor del sueño? El silencio es miedo, soledad, vigilia. Así, acompañada de sonidos, de roncos movimientos, ella va a dormir... Buenas noches, buenas noches... ¡Qué absurdo! ¿Por qué va a tenerles miedo? Sus pies de fierro están apernados al suelo; no pueden caminar. Apernados, iqué lástima! En la palma de su mano abierta, Juana contempla las cuatro pastillas. ¿Serán muchas? No; ella no quiere morir, y menos ahora. ¿Serán demasiadas? Son las últimas pastillas y aún faltan un día y una noche, una noche y un día. ¡Qué estúpido sería que se le fueran durmiendo! Con paso incierto se dirige a la sala de baño, y, una a una las deja caer en la tasa del silencioso. Largo rato después que el cono de agua se ha serenado, contempla el blanco fondo. No tiene sueño. Nunca más tendrá sueño. El sueño es para los de afuera... Tiene mucho que vivir. Mucho que aprender. "Juana... Juana... -vibra la voz-. Juana, ven". Deslizándose, la mujer se aproxima a la máquina. Sube, baja; derecha, izquierda. Sus manos trémulas aprisionan violentamente el émbolo, y con el esfuerzo de todos sus músculos, trata de detenerlo. El impulso la arrastra hacia abajo, hacia arriba, derecha, izquierda... Por entre sus dedos, el aceite se escurre; el metal está duro, caliente. Arriba, abajo, derecha, izquierda... Perfora, quema. El suelo vibra, la 
banca vibra, Juana siente la caricia contenida y adormecedora de esa vibración, en su cuerpo enervado y hambriento. De pronto, en su cerebro alucinado aparecen una imagen y otra. En una esquina, un hombre y una mujer, ocultos, se besan. Una pieza, un hombre desnudo; el olor denso. Los ojos malignos de su prima. " ¡Sal de aquí, chiquilla intrusa!". Diez años, angustia. Y esos ruidos en las noches, quejas, sollozos, risas entrecortadas, como de duendes. Silencio. Manos que se deslizan en la penumbra. Escenas violentas, en primer plano, en la pantalla de un cine de barrio. El hombre y la mujer... Siempre el hombre y la mujer. Más adelante supo que eso no tenía nada de maligno ni de prohibido ni de angustioso, pero lo supo a través de un raciocinio, de novelas baratas, de confidencias hechas entre risas forzadas que la dejaron molesta, curiosa, intranquila. Pero su experiencia no vino. No apreciaba que eso, el sexo, hubiera sido muy importante en su vida. Solo curiosidad, pena, desazón. ¿Sentirse enamorada? ¿Desear el contacto de un hombre?... Sí, tal vez. Tenía entonces dieciséis años, clases de costura, y apareció aquel muchacho rubio que vendía pasteles a la salida. Sí; a él lo quiso. Él nunca se dio cuenta; con seguridad no se fijó en ella. Aunque quién sabe... Algo hubo, algo le dijeron. Eran crueles las muchachas a esa edad. ¿Fue ese su primer amor? (Amor: ninguna marca, ningún recuerdo, nada). Y esa pregunta, esa eterna pregunta formulada en todos los lugares públicos, bancos, hospitales, tiendas, sin concederle importancia, ¿casada o soltera? "Soltera, señorita, obrera...". Sin pertenecer a nadie, sin destino ni destinatario. Señorita Juana, a secas. Como un disparo a quemarropa, el dolor la conmociona, violento... Asustada, la mujer se mira la mano, donde un reborde oscuro comienza a hincharse. Sus manos aceitadas fueron bajando cada vez más por el émbolo, hasta que un costado de la palma fuera mordido por el filo redondo. ¿Acaso la máquina, celosa de sus recuerdos, ha acelerado el ritmo? No; iqué estupideces se le ocurren! Lanza una mirada oblicua sobre el mecanismo, como si pretendiera sorprenderlo. Nada, está trabajando indiferente: arriba, abajo, derecha, izquierda... Nuevamente sus manos aprisionan el émbolo y la vibración la invade. Sus hombros, sus pechos, su cuerpo entero es impulsado adelante, atrás, vibrando, vibrando; derecha, izquierda, vibrando. Un deseo tiránico se apodera de ella. Quiere sentir; no importa qué, pero sentir violentamente..., violentamente. Ambivalencia de dolor y placer, miedo y entrega. Su respiración comienza a seguir el jadeo de la máquina y vive, vive... Aferrada a ese ser tibio, duro, firme, viscoso, dominante, quiere más. Derecha, izquierda, arriba, abajo. Hasta la locura, hasta el dolor. La cabeza inclinada, vuelta hacia el émbolo; los brazos abandonados, laxos, la mujer sueña. Sueña un sueño rojo, negro, violento, amarillo brillante; violento. Chispazos, ondas que ondulan la envuelven; ondas que salen de su ser, ondas, desconocidas, voluptuosas; extrañas prolongaciones que parecieran salir de un ser ajeno. Apetitos insospechados, fiebre, risa, cavidades blandas que ceden, rígidos metales que hieren. Lentamente, el dolor traspasa redes de nervios que estallan rasgando zonas olvidadas. El calor, la fricción, la fuerza, queman con rudo contacto mecánico, encendiendo, iluminando esa que fuera una vida gris. Con claridad inusitada, Juana comprende que no podrá volver, que no quiere seguir su vida opaca. No más días vacíos. Esta es su aventura, ¡la única!, la tantas veces ansiada. ¡Y está sucediendo!... Nunca más "Buenos días, señorita Juana", "Llegará atrasada, señorita Juana"; no más horas perdidas contemplando 
el vivir ajeno. Ahora, ella también podrá contar... La escucharán, ella tendrá recuerdos. Recuerdos de cosas prohibidas, ocultas. ¿Volver? ¿Salir de ahí? Nunca más. ¿Volver?... ¡Jamás! El movimiento pide rendición; entrega hasta lo profundo, hasta lo ignorado. Desnudando el rechazo, la castidad, desde el fondo desquiciado de su experiencia célibe, la mujer entiende que ese ser la desea, la necesita, y que su expresión es quemante, lacerante. Algo quiere entrar y golpea. Golpea, quiere entrar... iy entra! Entonces el dolor lo llena todo y la sangre ciega sus ojos, el negro aceite se introduce en las heridas y el acero quiere ser piel; las uñas, tuercas; los tendones y engranajes, la energía y la vida, el zumbido y el grito se funden, se mezclan..., se aman.

La carne calla. El acero sigue buscando, arriba, abajo, derecha, izquierda. Enloquecido, implacable, posesivo. Arriba, abajo, derecha, izquierda sobre el silencio. 